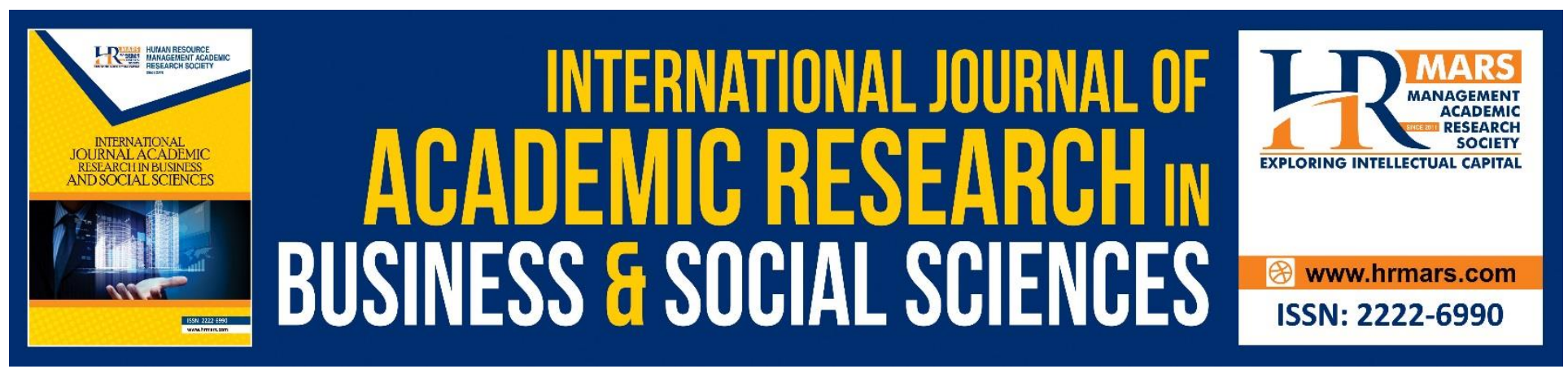

\title{
A Simple Growth Model Based on Neoclassical Growth, Monopolistic Competition, and Walrasian General Equilibrium Theories
}

\author{
Wei-Bin Zhang
}

To Link this Article: http://dx.doi.org/10.6007/IJARBSS/v9-i3/5758

DOI: $\quad 10.6007 /$ IJARBSS/v9-i3/5758

Received: 26 Jan 2019, Revised: 25 Feb 2019, Accepted: 30 March 2019

Published Online: 31 March 2019

In-Text Citation: (Zhang, 2019)

To Cite this Article: Zhang, W.-B. (2019). A Simple Growth Model Based on Neoclassical Growth, Monopolistic Competition, and Walrasian General Equilibrium Theories. International Journal of Academic Research in Business and Social Sciences, 9(3), 1005-1027.

Copyright: @ 2019 The Author(s)

Published by Human Resource Management Academic Research Society (www.hrmars.com)

This article is published under the Creative Commons Attribution (CC BY 4.0) license. Anyone may reproduce, distribute, translate and create derivative works of this article (for both commercial and non-commercial purposes), subject to full attribution to the original publication and authors. The full terms of this license may be seen at: http://creativecommons.org/licences/by/4.0/legalcode

Vol. 9, No. 3, 2019, Pg. 1005 - 1027

Full Terms \& Conditions of access and use can be found at http://hrmars.com/index.php/pages/detail/publication-ethics 


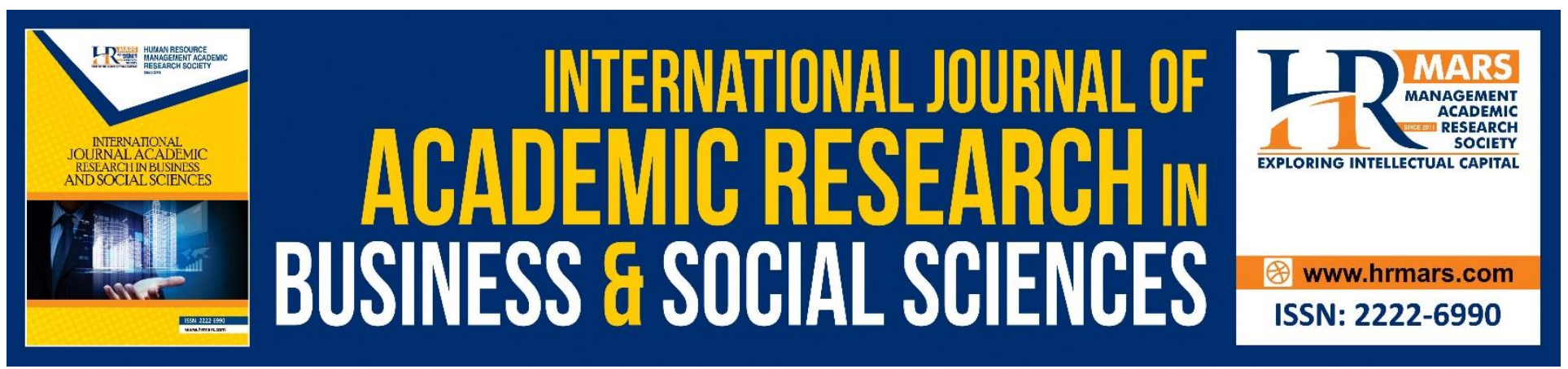

\title{
A Simple Growth Model Based on Neoclassical Growth, Monopolistic Competition, and Walrasian General Equilibrium Theories
}

\author{
Wei-Bin Zhang \\ Ritsumeikan Asia Pacific University, Japan
}

\begin{abstract}
The purpose of this study is to examine economic growth and income and wealth distribution on the basis of Walrasian general equilibrium theory, neoclassical growth theory, and Dixit-Stiglitz monopolistic competitive theory. It makes a unique contribution to the literature of economic growth with perfect competition and monopolistic competition by integrating the basic economic mechanisms in the Walrasian general equilibrium model, the Solow one-sector growth model, and the Dixit-Stiglitz model. The final goods sector in our approach is based on Solow's one-sector growth model. The issues of distribution are referred to the Arrow-Debreu theory. The market mechanism of perfect competitive markets is based on traditional neoclassical growth theory. We described imperfect competition on the approach basically developed by Dixit and Stiglitz. The paper unifies these approaches by applying the utility function and the concept of disposable income proposed by Zhang. We also deviate from the DixitStiglitz by assuming that non-zero profits are distributed to households. We build and then simulate the model for a three-group economy. We examine the effects of changes in some parameters on transitory processes and long-term equilibrium structure.
\end{abstract}

Keywords: Solow Growth Model, Walrasian General Equilibrium, Dixit-Stiglitz Model, Monopolistic Competition, Profit Distribution

\section{Introduction}

Economic reality of modern economies is characterized by co-existence of markets with perfect competition, monopolistic competition, monopoly (state planning), and different types of games. In modern growth theory, there are two main approaches with (proper) microeconomic foundations. Traditional neoclassical growth theory is mostly concerned with capital accumulation with economic structure but a homogeneous population (which implies no insight into income and wealth distribution among households). New dynamic economic theory is mainly concerned with perfect and monopolistic competition and knowledge creation and utilization without a proper mechanism for dealing wealth accumulation. The two approaches failed to deal with economic growth with heterogeneous households. 
Economic dynamic theory lacks proper modelling frameworks for explaining dynamic issues related to income and wealth distributions, even though Walrasian theory provides a rational explanation about distribution of income and wealth in a static world. It is a great challenge to create a theory which includes the basic mechanisms in these approaches in a single framework. with microeconomic foundation. The unique contribution to the literature of economic growth is integrating the basic economic mechanisms in the Walrasian general equilibrium model, the Solow one-sector growth model, and the Dixit-Stiglitz model.

Modelling of monopolistic competition has recently become very popular in building macroeconomic models on the basis of microeconomic foundation. The ideas and modelling strategies in the literature of new economic theory enable economists to explain many well observed but not properly modelled phenomena. The theory of monopolistic competition has been applied to different issues of economics related to economic structures, economic growth, economic geography, international trade, and innovation and technological diffusion (e.g., Dixit and Stiglitz, 1977; Krugman, 1979, 1980; Lancaster, 1980; Waterson, 1984; Grossman and Helpman,1990; Benassy, 1996; Bertoletti and Etro, 2015; Nocco, et. al., 2017; and Parenti, et.al., 2017). Although macroeconomics based on monopolistic competition theory has provided many important insights into contemporary economic complexity, as far as economic dynamics is concerned, the approach has not succeeded in modelling wealth accumulation with heterogeneous households. Issues related to income and wealth distribution are important for understanding many problems of political economy in modern world. The purpose of this study is to integrate neoclassical growth theory and Walrasian general equilibrium theory with monopolistic competition. We apply the main economic growth mechanism in neoclassical growth theory to model wealth accumulation and the general equilibrium economic principle to model income and wealth distribution. In our approach, perfect competition and monopolistic competition co-exist

This study is concerned with the role of perfect competition and monopolistic competition on economic growth. Coexistence of perfect competition and monopolistic competition in macroeconomic dynamics with wealth accumulation is introduced by, for instance, Romer (1990). The economy has two sectors. The final goods sector is characterized by perfect competition and produces a single globally homogenous capital goods with identical firms. The middle goods sector is characterized by monopolistic competition and produces a variety of different goods with different firms. We model production and consumption of middle goods by following analytical framework for monopolistic competition by Dixit and Stiglitz (1977). Dixit and Stiglitz emphasize diversity of consumption on consumption structure. We base Solow's one-sector growth model to describe the final goods sector. Solow (1956) published the seminal work for development of neoclassical growth theory. Our market mechanism of perfect competitive markets is based on traditional neoclassical growth theory. Neoclassical growth theory is mainly concerned with wealth accumulation with perfect competition. The Solow model analyzes how the economic growth rate is determined with exogenous saving rate, exogenous technology, and exogenous population growth. Over years strict assumptions in the Solow model has been relaxed in different directions (e.g., Burmeister and Dobell, 1970; Azariadis, 1993; Barro and Sala-i-Martin, 1995; Jones and Manuelli, 1997; Ben-David and Loewy, 2003; and Zhang, 2008). But most all of these extensions are limited to perfectly competitive markets. This study extends neoclassical growth model by taking account of monopolistic competition. 
Another important issue of this research is related to dynamics of income and wealth distribution. Macroeconomics lacks a proper framework for analyzing issues related to growth and income and wealth distribution between heterogeneous households. This study deals with growth and inequality with perfect and monopolistic competition within an integrated framework of Walrasian general equilibrium theory (e.g., Walras, 1874; Arrow and Debreu, 1954; Debreu, 1959; Arrow and Hahn, 1971; and Mas-Colell et al., 1995) and neoclassical growth theory. It is well known that the Walrasian theory is mathematically refined but is not very useful with regard to dynamics of wealth accumulation with heterogeneous households (e.g., Morishima, 1964, 1977; Diewert, 1977; Eatwell, 1987; Dana et al. 1989; and Montesano, 2008; Impicciatore et al., 2012). Our model also studies dynamic interdependence between endogenous labor supply, economic growth and profit sharing. There are many research publications in endogenous labor supply, family structure, working hours and the valuation of traveling time with division of labor and leisure (Becker, 1976; Gomme et al., 2001; Campbell and Ludvigson, 2001; Gutierrez, 2003; Tassel, 2004; Stotsky, 2006). We apply Zhang's approach (Zhang, 2005) to deal with endogenous time with wealth accumulation in an economy with heterogeneous households.

We unify the different approaches by applying the utility function and the concept of disposable income proposed by Zhang $(2005,2008)$. We make an extension of Zhang's model with homogeneous population (Zhang, 2018) by introducing heterogenous households. The rest of the paper is organized as follows. Section 2 constructs the growth model of heterogenous households under perfect competition and monopolistic competition. Section 3 analyzes properties of the global economy and simulates the economic system. Section 4 conducts comparative dynamic analysis in some parameters. Section 5 concludes the study.

\section{Modelling Returns to Scale and Growth with Heterogenous Households}

We now build a model of heterogeneous households to analyze economic growth with endogenous capital accumulation under perfect competition and monopolistic competition. We integrate the three basic models in economic theory within a comprehensive framework. We base Walrasian general theory on determination of price equilibrium in an economy with heterogeneous households. We base Solow's one-sector growth model to describe the final goods sector with perfect competition. We describe imperfect competition on the approach developed by Dixit and Stiglitz. We unify the different approaches by applying the utility function and the concept of disposable income proposed by Zhang. We now describe the model.

\section{The total labor force}

The population is classified into $J$ groups according to human capital and preference. Let subscripts $\mathrm{j}$ stand for group j , j $=1, \ldots, \mathrm{J}$. We use $\mathrm{T}_{j}(t)$ to stand for the work time of household $\mathrm{j}$ and $N(t)$ the flow of labor services used at time $t$ for production. We have $N(t)$ as follows:

$$
N(t)=\sum_{j=1}^{J} h_{j} T_{j}(t) \bar{N}_{j},
$$

where $\bar{N}_{j}$ and $h_{j}$ are respectively the population and the level of human capital of group $j$. In this study for simplicity of analysis we assume $\bar{N}_{j}$ and $h_{j}$ to be fixed. 


\section{The final goods sector}

The final goods sector is almost the same as the industrial sector in the Solow model. Let $F(t), K(t)$ and $\widetilde{N}(t)$ stand for, respectively, output of the final goods sector, capital input and labor input. As in Solow (1956), we apply the Cobb-Douglas production function as follows:

$$
F(t)=A K^{\alpha}(t) \widetilde{N}^{\beta}(t), \quad 0<\alpha, \beta<1, \alpha+\beta=1, \quad(2)
$$

in which $A, \alpha$ and $\beta$ are coefficients. We use capital good as a medium of exchange. It is taken as numeraire. Physical capital depreciates at a constant exponential rate $\delta_{k}$. We use $w(t)$ and $r(t)$, to stand for, respectively, the wage rate and the rate of interest. We have the profit of the final goods sector as follows:

$$
\pi_{0}(t)=F(t)-\left(r(t)+\delta_{k}\right) K(t)-w(t) \widetilde{N}(t)
$$

Maximizing profit implies the following marginal conditions:

$$
R(t)=\frac{\alpha F(t)}{K(t)}, w(t)=\frac{\beta F(t)}{\widetilde{N}(t)}, w_{j}(t)=h_{j} w(t),
$$

where $w_{j}(t)$ stand for the wage rate of the representative household in group $j$ and $R_{\delta}(t) \equiv r(t)+$ $\delta_{k}$. We thus complete describing the behavior of the final goods sector. From (3), we have $w_{j}(t) / w_{m}(t)=h_{j} / h_{m}$. This relation is due to assumption that there is no discrimination in the sense that any one is paid per unit of time according to one's work efficiency.

\section{Disposable income and profit share}

This study applies a new approach to modeling behavior of households. The model is proposed by Zhang (1993) and has been applied to different fields of economics (e.g., Zhang, 2005, 2008). We use $\bar{k}_{j}(t)$ to represent group $j^{\prime} s$ household wealth. As in Zhang (2018), we assume that the total profit of all the firms of the middle goods sector is shared among the households. We use $\pi_{j}(t)$ to stand for the profit shared by the representative household in group $j$. The current income of the representative household in group $j$ :

$$
y_{j}(t)=r(t) \bar{k}_{j}(t)+h_{j} T_{j}(t) w(t)+\pi_{j}(t) .
$$

The household disposable income $\hat{y}_{j}(t)$ is the sum of the current disposable income and the value of wealth:

$$
\hat{y}_{j}(t)=y_{j}(t)+\bar{k}_{j}(t)
$$

The concept of disposable income in our approach is different from the traditional concept of disposable income which is equal to the current income in our approach. Our disposable income is the sum of the value of what one earns currently and the value of what one owns. In this study we assume that transaction costs in terms of money and time are omitted. This implies, for instance, one can sell one's asset to purchase middle goods for consumption.

\section{Budgets and composite good for aggregating middle goods}

The representative household spends the disposable income on saving $s_{j}(t)$, on consuming final goods $d_{j}(t)$, and on consuming middle goods $\tilde{c}_{j}(\varepsilon, t)$. Here, $\tilde{c}_{j}(\varepsilon, t)$ stands for the amount of variety $\varepsilon$ that is consumed by group $j$ 's representative household. Let variety $\varepsilon$ distribute within the range from 0 to $n$, $\varepsilon \in[0, n]$. We follow Dixit and Stiglitz (1977) in describing consumption of middle goods. The composite good for each group is introduced as follows: 


$$
c_{j}(t)=\left(\int_{0}^{n} \tilde{c}_{j}^{\bar{\theta}}(\varepsilon, t) d \varepsilon\right)^{1 / \bar{\theta}}, 1>\bar{\theta}_{j}>0,
$$

where $\bar{\theta}$ is a positive parameter. The above function of constant elasticity of substation is widely applied in the recent literature of monopolistic competition (see also Spence, 1976; and Tirole, 1988).

Let the price of $\tilde{c}_{j}(\varepsilon, t)$ be denoted by $\tilde{p}(\varepsilon, t)$. The disposable income is spent on savings, consuming final goods, and consuming middle goods. We have the budget constraint as follows:

$$
d_{j}(t)+\int_{0}^{n} \tilde{p}(\varepsilon, t) \tilde{c}_{j}(\varepsilon, t) d \varepsilon+s_{j}(t)=\hat{y}_{j}(t) .
$$

Denote $\bar{T}_{j}(t)$ the leisure time at time $t$ and the $T_{0}$ (fixed) available time for work and leisure. The time constraint is expressed by:

Insert the above equation in (4)

$$
T_{j}(t)+\bar{T}_{j}(t)=T_{0}
$$

where we also use (5) and

$$
\hat{y}_{j}(t)=R(t) \bar{k}_{j}(t)-h_{j} \bar{T}_{j}(t) w(t)+W_{j}(t),
$$

Substituting (8) into (7) yields:

$$
R(t) \equiv 1+r(t), W_{j}(t) \equiv h_{j} T_{0} w(t)+\pi_{j}(t)
$$

where

$$
h_{j} \bar{T}_{j}(t) w(t)+d_{j}(t)+\int_{0}^{n} \tilde{p}(\varepsilon, t) \tilde{c}_{j}(\varepsilon, t) d \varepsilon+s_{j}(t)=\bar{y}_{j}(t),(9)
$$

$$
\bar{y}_{j}(t) \equiv R(t) \bar{k}_{j}(t)+W_{j}(t)
$$

\section{Utility functions and optimal behavior}

We assume that utility level $U_{j}(t)$ is dependent on $\bar{T}_{j}(t), d_{j}(t), c_{j}(t)$ and $s_{j}(t)$ as follows:

$$
U_{j}(t)=\bar{T}_{j}^{\sigma_{0 j}}(t) c_{j}^{\chi_{0 j}}(t) d_{j}^{\xi_{0 j}}(t) s_{j}^{\lambda_{0 j}}(t), \sigma_{0 j}, \xi_{0 j}, \lambda_{0 j}, \chi_{0 j}>0,(10)
$$

where $\sigma_{0 j}$ is the propensity to use leisure time, $\xi_{0 j}$ is the propensity to consume final good, $\chi_{0 j}$ is the propensity to consume intermediates, and $\lambda_{0 j}$ is the propensity to save. Many research papers with formal modelling have been published on dynamic interdependence between economic growth and time allocation. In the literature of economic development, reallocation of labor from households to the market in association of economic growth are modelling in different approaches (for instance, Becker, 1965; Goodfriend and McDermott, 1995; Kelly, 1997; Edmonds and Pavcnik, 2006; and Ferber and Green, 2007). This study takes on a simplified form of leisure time.

The problem is to maximize utility (10) subject to budget constraint (9). We apply the two-stage method to solve the optimization problem (e.g., Dixit-Stiglitz, 1977; Chang, 2012). In the first stage, we imagine that there is a price $p(t)$ for $c_{j}(t)$. The budget for the question is:

$$
h_{j} w(t) \bar{T}_{j}(t)+d_{j}(t)+p(t) c_{j}(t)+s_{j}(t)=\bar{y}_{j}(t) \text {. }
$$

It is straightforward to show that the optimal solution is given by:

where

$$
\begin{gathered}
h_{j} w(t) \bar{T}_{j}(t)=\sigma_{j} \bar{y}_{j}(t), d_{j}(t)=\xi_{j} \bar{y}_{j}(t), p(t) c_{j}(t)=\chi_{j} \bar{y}_{j}(t), \\
s_{j}(t)=\lambda_{j} \bar{y}_{j}(t),(12)
\end{gathered}
$$

$$
\sigma_{j} \equiv \rho_{j} \sigma_{0 j}, \quad \xi_{j} \equiv \rho_{j} \xi_{0 j}, \quad \chi_{j} \equiv \rho_{j} \chi_{0 j}, \lambda_{j} \equiv \rho_{j} \lambda_{0 j}, \quad \rho_{j} \equiv \frac{1}{\sigma_{0 j}+\xi_{0 j}+\chi_{0 j}+\lambda_{0 j}} .
$$


The second-stage maximization is formed as follows: maximize $c_{j}(t)$ by choosing $\tilde{c}_{j}(\epsilon, t)$ subject to:

$$
\int_{0}^{n} \tilde{p}(\varepsilon, t) \tilde{c}_{j}(\varepsilon, t) d \varepsilon=p(t) c_{j}(t) .
$$

Introduce the following Langrangian function:

$$
\mathcal{L}_{j}(t) \equiv\left(\int_{0}^{n} \tilde{c}_{j}^{\bar{\theta}}(\varepsilon, t) d \varepsilon\right)^{1 / \bar{\theta}}+\hbar_{j}(t)\left\{p(t) c_{j}(t)-\int_{0}^{n} \tilde{p}(\varepsilon, t) \tilde{c}_{j}(\varepsilon, t) d \varepsilon\right\},
$$

where $\hbar_{j}(t)$ is the Lagrangian multiplier. From (12) we get the following first-order conditions:

$$
\begin{gathered}
\frac{\partial \mathcal{L}_{j}(t)}{\partial \tilde{c}_{j}(\varepsilon, t)}=c_{j}^{1-\bar{\theta}}(t) \tilde{c}_{j}^{\bar{\theta}-1}(\varepsilon, t)-\hbar_{j}(t) \tilde{p}(\varepsilon, t)=0, \\
\frac{\partial \mathcal{L}_{j}(t)}{\partial \hbar_{j}(t)}=p(t) c_{j}(t)-\int_{0}^{n} \tilde{p}(\varepsilon, t) \tilde{c}_{j}(\varepsilon, t) d \varepsilon=0 .
\end{gathered}
$$

From the first equations in (15), we have:

From (16), we have:

$$
c_{j}^{1-\bar{\theta}}(t) \tilde{c}_{j}^{\bar{\theta}-1}(\varepsilon, t)=\hbar_{j}(t) \tilde{p}(\varepsilon, t) .
$$

$$
\frac{\tilde{c}_{j}(\varepsilon, t)}{\tilde{c}_{j}(\mu, t)}=\left(\frac{\tilde{p}(\varepsilon, t)}{\tilde{p}(\mu, t)}\right)^{1 /(\bar{\theta}-1)}=\left(\frac{\tilde{p}(\varepsilon, t)}{\tilde{p}(\mu, t)}\right)^{-\omega}, \bar{\theta}=1-\frac{1}{\omega} .
$$

where $\omega_{j}$ is the elasticity of substitution between any two varieties:

From (15) we also have:

$$
\frac{(\tilde{p}(\varepsilon, t) / \tilde{p}(\mu, t))}{\left(\tilde{c}_{j}(\varepsilon, t) / \tilde{c}_{j}(\mu, t)\right)} \frac{d\left(\tilde{c}_{j}(\varepsilon, t) / \tilde{c}_{j}(\mu, t)\right)}{d(\tilde{p}(\varepsilon, t) / \tilde{p}(\mu, t))}=\omega .
$$

$$
\tilde{c}_{j}(\varepsilon, t) \tilde{p}(\varepsilon, t)=\left(\frac{\tilde{p}(\varepsilon, t)}{\tilde{p}(\mu, t)}\right)^{\gamma} \tilde{p}(\varepsilon, t) \tilde{c}_{j}(\mu, t),
$$

where $\gamma \equiv 1 /(\bar{\theta}-1)$. From the above equations, we have:

$$
\begin{gathered}
p(t) c_{j}(t)=\chi_{j} \bar{y}_{j}(t)=\int_{0}^{n} \tilde{p}(\varepsilon, t) \tilde{c}_{j}(\varepsilon, t) d \varepsilon=\frac{\tilde{c}_{j}(\gamma, t)}{\tilde{p}^{\gamma}(\gamma, t)} \int_{0}^{n} \tilde{p}^{\bar{\theta} \gamma}(\varepsilon, t) d \varepsilon \\
=\frac{\tilde{c}_{j}(\gamma, t) P_{j}(t)}{\tilde{p}^{\gamma}(\gamma, t)}, \quad \text { (18) }
\end{gathered}
$$

where

$$
P_{j}(t) \equiv \int_{0}^{n} \tilde{p}^{\bar{\theta} \gamma}(\varepsilon, t) d \varepsilon
$$

Hence, we have:

$$
\tilde{c}_{j}(\varepsilon, t)=\chi_{j} \bar{y}_{j}(t) \tilde{p}^{\gamma}(\varepsilon, t) P_{j}^{-1}(t) .
$$

From (19), we get

$$
p(t)=\frac{\chi_{j} \bar{y}_{j}(t)}{c_{j}(t)}=\left(\int_{0}^{n} \tilde{c}_{j}^{\bar{\theta}}(\varepsilon, t) d \varepsilon\right)^{-\frac{1}{\bar{\theta}}} \chi_{j} \bar{y}_{j}(t)=P_{j}(t)^{\frac{1}{\bar{\theta} \gamma}} .
$$

The value share of variety $\varepsilon$ in the total value of intermediates for consumption is: 
where

$$
\varphi(\varepsilon, t)=\frac{\tilde{p}(\varepsilon, t) \tilde{c}(\varepsilon, t)}{\bar{y}(t)}
$$

$$
\bar{y}(t) \equiv \sum_{j=1}^{J} \bar{N}_{j} \int_{0}^{n} \tilde{p}(\varepsilon, t) \tilde{c}_{j}(\varepsilon, t) d \varepsilon, \quad \tilde{c}(\varepsilon, t) \equiv \sum_{j=1}^{J} \tilde{c}_{j}(\varepsilon, t) \bar{N}_{j} .
$$

\section{The household's wealth accumulation}

The change in the household's wealth saving minus dissaving:

$$
\dot{k}_{j}(t)=s_{j}(t)-\bar{k}_{j}(t)
$$

\section{The middle goods sector}

Markets of middle goods are characterized of monopolistic competition. No firm in the middle goods sector can produce a product with an attribute that is very close to any given attribute of any other product. They are assumed to act atomistically in that no firm take account of possible impacts of its decisions on any other firm. Let $x(\varepsilon, t)$ stand for the output level of the producer of variety $\varepsilon$. We have the condition that demand equals supply as follows:

$$
\sum_{j=1}^{J} \tilde{c}_{j}(\varepsilon, t) \bar{N}_{j}=x(\varepsilon, t)
$$

All meddle goods are produced with the same cost function. The labor force used in producing each good is linearly related to output as follows:

$$
l(\varepsilon, t)=\tilde{\alpha}+\tilde{\beta} x(\varepsilon, t),
$$

where $l(\varepsilon, t)$ is labor force used in producing good $\varepsilon, \tilde{\alpha}$ is a fixed cost, and $\tilde{\beta}$ is a positive coefficient. The total labor force $N_{x}(t)$ used by the middle goods sector is the sum of labor force used by all the firms:

$$
N_{x}(t)=\int_{0}^{n} l(\varepsilon, t) d \varepsilon
$$

The producer of variety $\varepsilon$ has the following profit:

$$
\bar{\pi}(\varepsilon, t)=\tilde{p}(\varepsilon, t) x(\varepsilon, t)-(\tilde{\alpha}+\tilde{\beta} x(\varepsilon, t)) w(t) .(26)
$$

The symmetry of the problem implies that all immediate firms will produce the same quantity at the same price. We thus can use the shorthand notation:

$$
x(t)=x_{j}(\varepsilon, t), \pi(t)=\bar{\pi}(\varepsilon, t), \tilde{p}(t)=\tilde{p}(\varepsilon, t), \text { for all } \varepsilon .
$$

From (23) and (26), we have:

Insert (19) in (28)

$$
\bar{\pi}(t)=(\tilde{p}(t)-\tilde{\beta} w(t)) \sum_{j=1}^{J} \tilde{c}_{j}(\varepsilon, t) \bar{N}_{j}-\tilde{\alpha} w(t) .
$$

where

$$
\bar{\pi}(t)=(\tilde{p}(t)-\tilde{\beta} w(t)) \tilde{p}^{\gamma}(t) M(t)-\tilde{\alpha} w(t)
$$




$$
M(t) \equiv P_{j}^{-1}(t) \sum_{j=1}^{J} \chi_{j} \bar{y}_{j}(t) \bar{N}_{j}
$$

The first-order condition (i.e., $\partial \bar{\pi} / \partial \tilde{p}=0$ ) implies the following fixed-markup pricing rule:

$$
\tilde{p}(t)=\frac{\tilde{\beta} w(t)}{\bar{\theta}} \text {. }
$$

Insert (26) in (25)

$$
\bar{\pi}(t)=\vartheta w^{1+\gamma}(t) M(t)-\tilde{\alpha} w(t),
$$

where

$$
\vartheta \equiv\left(\frac{1}{\bar{\theta}}-1\right) \tilde{\beta}\left(\frac{\tilde{\beta}}{\bar{\theta}}\right)^{\gamma} .
$$

It should be noted that we obtain (26) under the consideration that a firm's action has negligible effect on $M(t)$. By the definitions, we have the profit share of the representative household:

$$
\pi_{j}(t)=\frac{\mu_{j} n \bar{\pi}(t)}{\bar{N}_{j}},
$$

where $n \bar{\pi}(t)$ is the total profit of the middle goods sector and share distribution is specified as follows:

$$
\sum_{j=1}^{J} \mu_{j}=1, \mu_{j} \geq 0 .
$$

It should be noted that there are different ways to deal with behavior of firms of middle goods. For instance, as in Krugman (1980), we might require $\bar{\pi}(t)=0$ as an equilibrium condition of free entry and exit. It is reasonable to assume that $\bar{\pi}(t)$ is positive and is invested as R\&D activities so that the number of firms become endogenous. Another condition is that the profit is shared between households and firms. In this study, for simplicity of analysis we accept (32).

\section{Demand and supply of final goods}

Capital good is the same as the commodity in the Solow model, which can be invested as capital good and consumed as consumer good. As change in capital stock is equal to the output of the final good sector minus the total consumption and depreciations of capital stock, we have:

$$
\dot{K}(t)=F(t)-d(t) \bar{N}-\delta_{k} K(t),(33)
$$

in which $F(t)$ is the output of capital goods, $d(t) \bar{N}$ is the consumption of capital goods, and $\delta_{k} K(t)$ is the total depreciation of physical capital.

\section{The national wealth}

The national wealth $\bar{K}(t)$ is equal to the sum of wealth values of all the households in the economy:

$$
\bar{K}(t)=\sum_{j=1}^{J} \bar{k}_{j}(t) \bar{N}_{j}
$$

As the national capital stock is fully employed, we have $\bar{K}(t)=K(t)$. 


\section{Labor and capital are Fully Employed}

The labor force is fully employed

$$
\widetilde{N}(t)+N_{x}(t)=\mathrm{N}(t)
$$

where $N_{x}(t)$ is the labor force employed by the middle goods sector:

$$
N_{x}(t)=n l(t)
$$

We built the model, which is based on Walrasian general equilibrium theory, the Solow model, and the Dixit-Stiglitz model. The rest of the paper studies properties and behavior of the national economy.

\section{The Dynamic Properties of the Model}

The previous section constructed a growth model of heterogenous households by integrating Walrasian general equilibrium theory, the Solow one-sector growth model with endogenous capital accumulation, and the Dixit-Stiglitz model with monopolistic competition. The economy is characterized by the neoclassical growth mechanism with perfect competition and monopolistic competition. We introduce a variable as follows:

$$
\begin{gathered}
z(t) \equiv \frac{r(t)+\delta_{k}}{w(t)}, \\
\left\{\bar{k}_{j}(t)\right\} \equiv\left(\bar{k}_{2}(t), \ldots, \bar{k}_{J}(t)\right) .
\end{gathered}
$$

The following lemma gives a computational program for following the movement of the economic system.

\section{Lemma}

The following differential equations determine the motion of the economic system:

$$
\begin{gathered}
\dot{\mathrm{z}}(t)=\Phi_{1}\left(z(t),\left\{\bar{k}_{j}(t)\right\}, \bar{k}_{3}(t)\right), \\
\dot{\bar{k}}_{2}(t)=\Phi_{2}\left(z(t), \bar{k}_{2}(t), \bar{k}_{3}(t)\right), \\
\dot{\bar{k}}_{3}(t)=\Phi_{3}\left(z(t), \bar{k}_{2}(t), \bar{k}_{3}(t)\right),
\end{gathered}
$$

where $\Phi_{j}$ are functions of $z(t)$ and $\left\{\bar{k}_{j}(t)\right\}$ defined in the Appendix. Moreover, all the variables can be expressed as functions of $z(t)$ and $\left\{\bar{k}_{j}(t)\right\}$ by the following procedure: $r(t)$ and $w(t)$ by (A3) $\rightarrow$ $\bar{k}_{1}(t)$ by $(\mathrm{A} 18) \rightarrow \tilde{p}(t)$ by $(30) \rightarrow \bar{y}_{j}(t)$ by $(\mathrm{A} 8) \rightarrow \bar{T}_{j}(t), d_{j}(t), s_{j}(t)$ by $(12) \rightarrow K(t)$ by $(32) \rightarrow \widetilde{N}(t)$ by $(\mathrm{A} 1) \rightarrow \pi_{j}(t)$ by (A6) $\rightarrow x(t)$ by (A9) $\rightarrow N_{x}(t)$ by (A9) $\rightarrow N(t)$ by (35) $\rightarrow F(t)$ by (A2) $\rightarrow \tilde{c}_{j}(t)$ by (19) $\rightarrow p(t)$ by $(20) \rightarrow l(t)$ by $(24) \rightarrow \varphi(t)$ by $(21) \rightarrow \bar{\pi}(t)$ by $(26) \rightarrow U_{j}(t)$ by (10).

The Lemma is proved in Appendix. As the expressions are complicated, we show dynamic behavior of the system by simulation for an economy with three groups. We specify the parameters as follows:

$$
\begin{gathered}
T_{0}=24, \bar{\theta}=0.4, \delta_{k}=0.05, A=1.4, n=200, \alpha=0.35, \tilde{\alpha}=0.01, \\
\tilde{\beta}=0.05, \bar{N}_{1}=10, \bar{N}_{2}=40, \bar{N}_{3}=100, h_{1}=4, h_{2}=1.5, h_{3}=1, \\
\mu_{1}=0.3, \mu_{2}=0.3, \mu_{3}=0.4, \lambda_{01}=0.7, \chi_{01}=0.1, \xi_{01}=0.2, \sigma_{01}=0.2, \\
\lambda_{02}=0.65, \chi_{02}=0.1, \xi_{02}=0.2, \sigma_{02}=0.25, \lambda_{03}=0.6, \chi_{03}=0.15, \\
\xi_{03}=0.25, \sigma_{03}=0.3 .
\end{gathered}
$$


INTERNATIONAL JOURNAL OF ACADEMIC RESEARCH IN BUSINESS AND SOCIAL SCIENCES

Vol. 9, No. 3, March, 2019, E-ISSN: 222 2-6990 @ 2019 HRMARS

The fixed available time is 24 and depreciation rate of physical capital is 5 percent. The three groups' populations are respectively 10, 40 and 100. Group 1 has higher human capital than group 2, and group 2 than group 3. The number of varieties of middle goods is 200 . The initial condition is as follows:

$$
z_{1}(0)=0.07, \quad \bar{k}_{2}(0)=90, \quad \bar{k}_{2}(0)=46 .
$$

We simulate the model. The simulation result is plotted in Figure 1. From the initial state, the national wealth and final goods sector's output fall. The national labor supply rises over time. The middle goods sector employs less labor force, while the final goods sector employs more. Each firm of the middle goods produces less and employs less. The rate of interest rises, while the wage rate rises. The changes in the other variables over time are given in the figure.
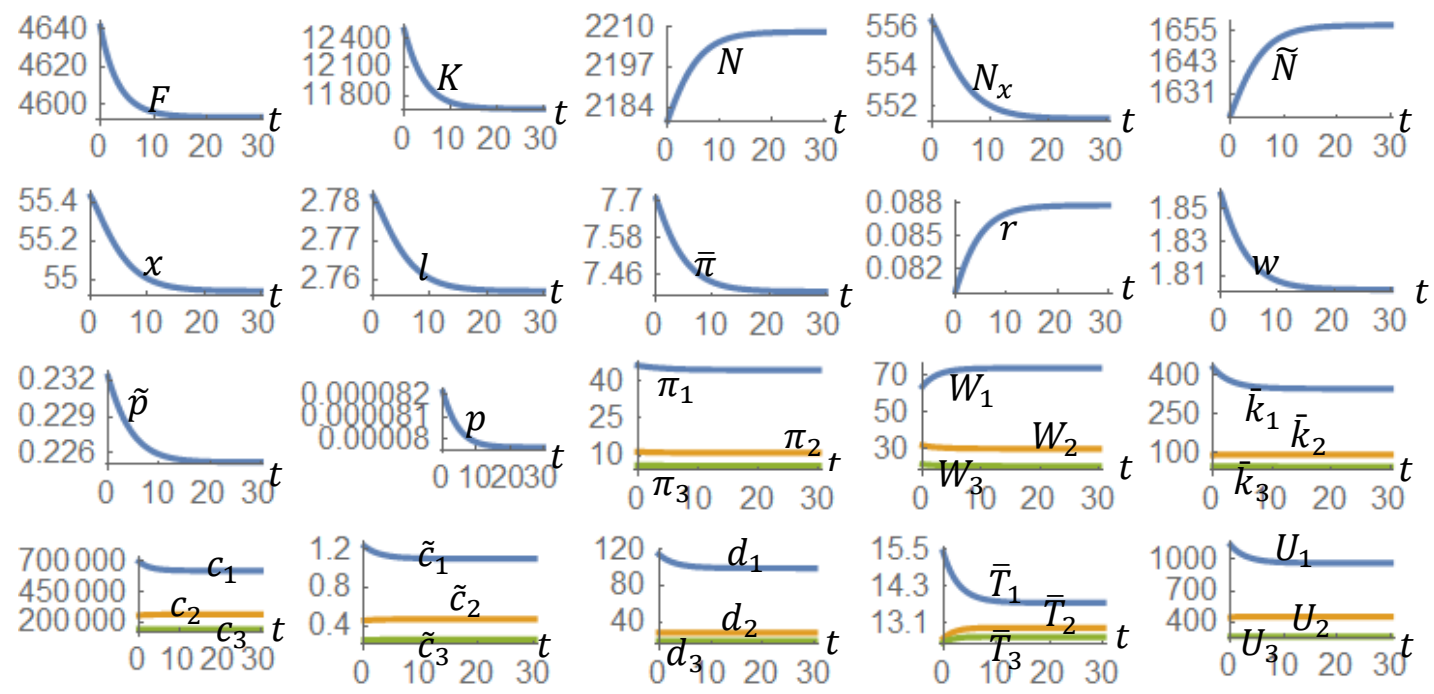

Figure 1. The Motion of the Economic System

The simulation shows that the economy becomes stationary in the long term. We confirm the equilibrium point as follows:

$$
\begin{gathered}
F=4593, K=11666, N=2208, N_{x}=551, \widetilde{N}=1657, x=55, l=2.76, \\
\bar{\pi}=7.41, r=0.088, w=1.8, \tilde{p}=0.23, p=0.00008, \pi_{1}=44.44, \\
\pi_{2}=11.1, \pi_{3}=5.93, W_{1}=73.8, W_{2}=29.9, W_{3}=20.5, \bar{k}_{1}=347, \bar{k}_{2}=90.96, \\
\bar{k}_{3}=45.6, c_{1}=622588, c_{2}=263598, c_{3}=143082, \tilde{c}_{1}=1.1, \tilde{c}_{2}=0.47, \\
\tilde{c}_{3}=0.25, d_{1}=99, d_{2}=28, d_{3}=19, \bar{T}_{1}=13.9, \bar{T}_{2}=12.9, \\
\bar{T}_{3}=12.6, U_{1}=965, U_{2}=450, U_{3}=262 .
\end{gathered}
$$

The eigenvalue at the equilibrium point is:

$$
-0.468, \quad-0.395, \quad-0.265 \text {. }
$$

This implies that the equilibrium point is locally stable. We can thus effectively carry out dynamic comparative analysis.

\section{Comparative Dynamic Analysis}


The previous section showed the motion of the economy. It is demonstrated that the system has a stable equilibrium point. We gave the Lemma which describes a computational procedure to calibrate the dynamic system. The lemma shows how to carry out comparative dynamic analysis. This section studies how the economy is affected when there are different exogenous shocks. We use a symbol $\bar{\Delta} x_{j}(t)$ to stand for the change rate of the variable, $x_{j}(t)$, in percentage due to changes in the parameter value.

\section{The elasticity of substitution between two varieties rises}

We first study what happens to the economy when the elasticity of substitution between two varieties is increased as follows: $\bar{\theta}=0.4 \Rightarrow 0.42$. The simulation result is plotted in Figure 1 . We see that a rise in $\bar{\theta}$ implies a fall in the price of middle goods and rise in the output of each firm in the middle goods sector. The profit of each firm and profit shared by each household fall. All the households increase work hours and the total labor supply is increased. The labor forces employed by the middle goods sector and by each firm rise and the labor force employed by the final goods sector rises. The output of the final goods sector and national wealth are reduced. The rate of interest rises and the wage rate falls. The aggregated good price rises and its consumption levels by the three groups fall. The wage incomes of the three groups are enhanced. The household has lower level of wealth and consumes less final goods. The utility levels of the three groups are all reduced.
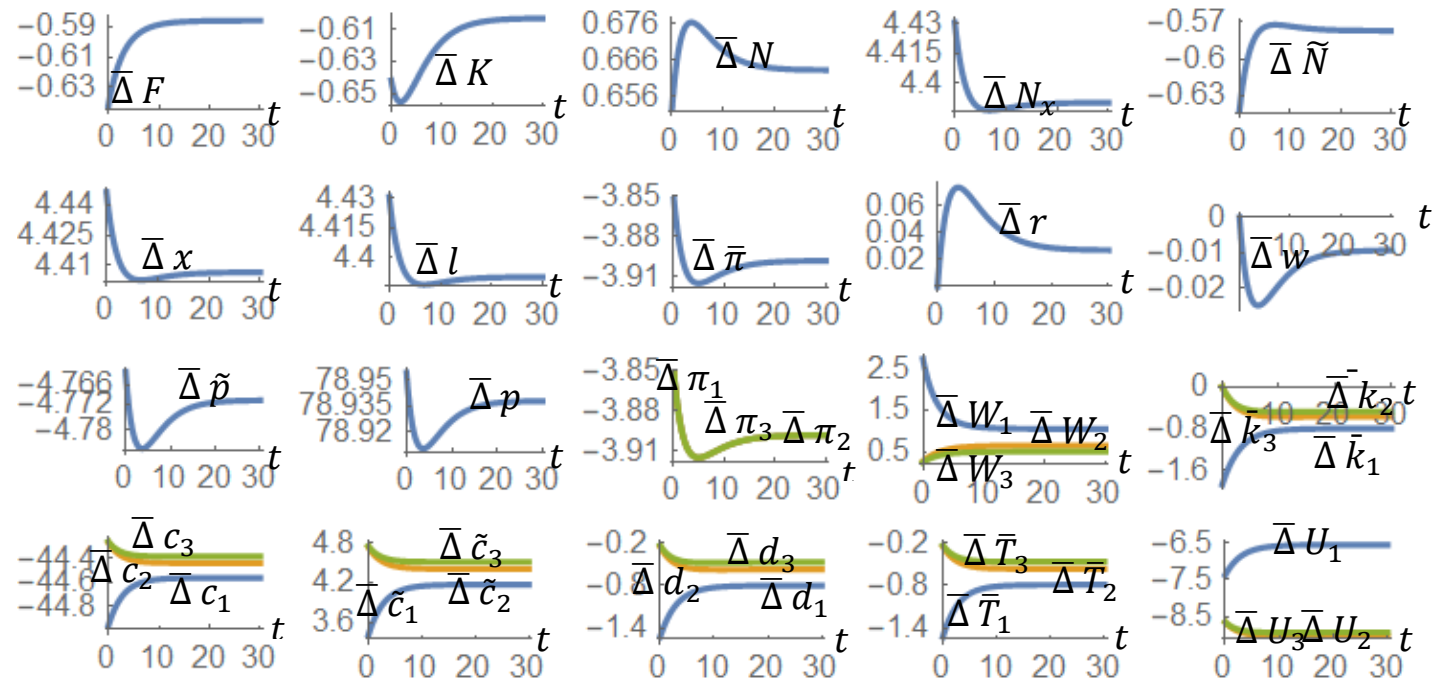

Figure 2. The Elasticity of Substitution between Two Varieties Rises

\section{Fixed labor cost of the middle goods firm is increased}

We now study the impact that the fixed labor cost of the middle goods firm is increased as follows: $\widetilde{\alpha}: 0.01 \Rightarrow 0.02$. The simulation result is plotted in Figure 3 . Each firm in the middle goods sectors produces less in association in fall of the price of middle goods. The profit of each firm and profit shared by each household fall. All the households increase work hours and the total labor supply is increased. The labor force employed by the middle goods sector rises. The labor force by each firm rises. The labor force employed by the final goods sector falls. The output of the final goods sector and national wealth are reduced. The rate of interest rises and the wage rate falls. The aggregated 
INTERNATIONAL JOURNAL OF ACADEMIC RESEARCH IN BUSINESS AND SOCIAL SCIENCES

Vol. 9, No. 3, March, 2019, E-ISSN: 222 2-6990 (C) 2019 HRMARS

good price rises and its consumption levels by the three groups fall. The wage incomes of the three groups are enhanced. The household has lower level of wealth and consumes less final goods. The utility levels of the three groups are all reduced.

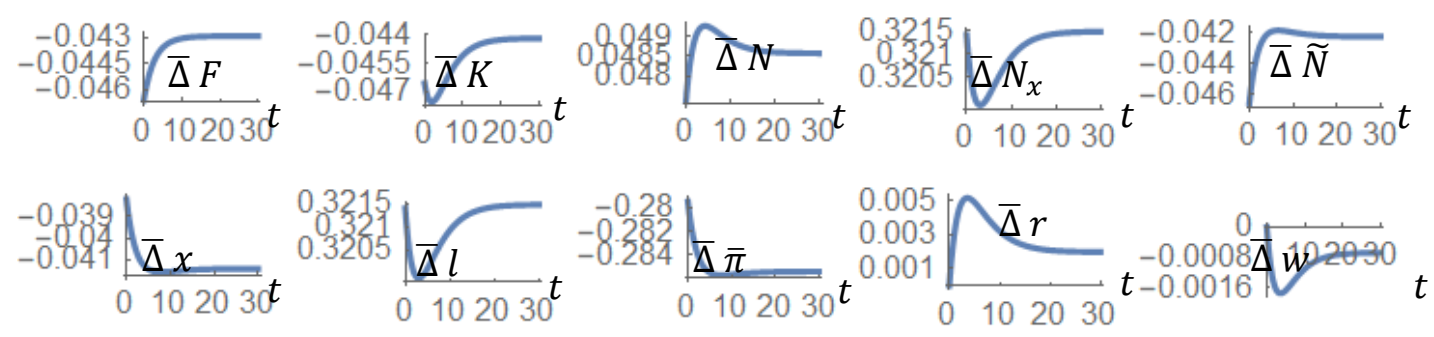

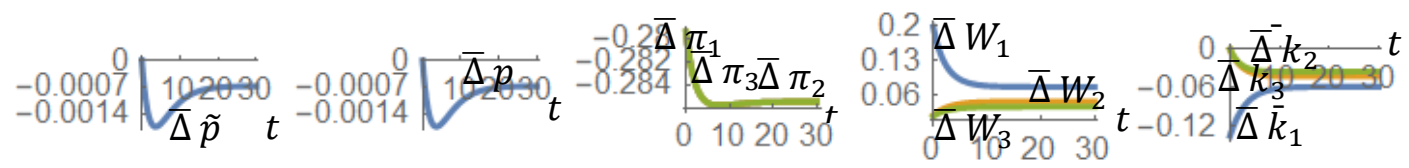

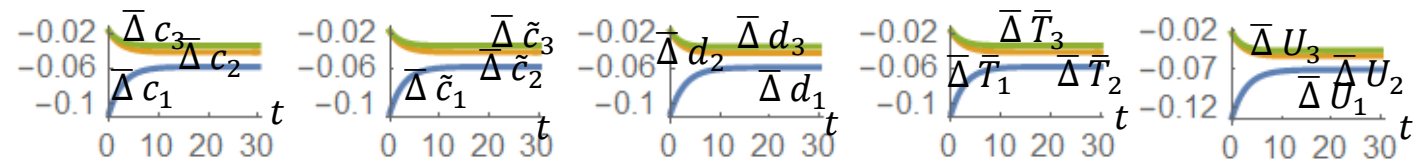

Figure 3. Fixed Labor Cost of the Middle Goods Firm is Increased

\section{A rise in variety of middle goods}

We now examine the impact of the following rise in variety of middle goods on the economy: $n: 200 \Rightarrow 210$. This may happen, for instance, due to (exogenous) innovation and introduction of new products. The simulation result is plotted in Figure 4. Macroeconomic variables are slightly affected. The consumption levels of each firm's product and each firm's production activities are strongly affected. The household utility levels are enhanced (due to the effect of love of variety).
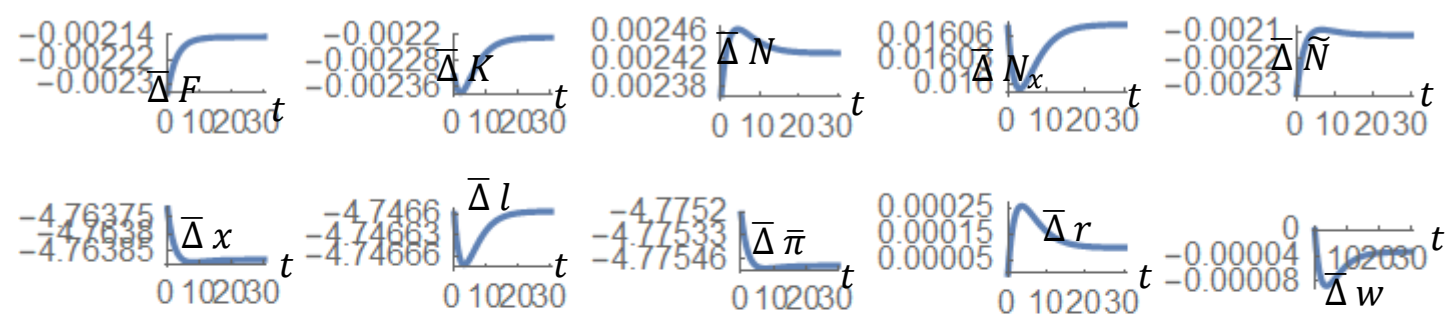

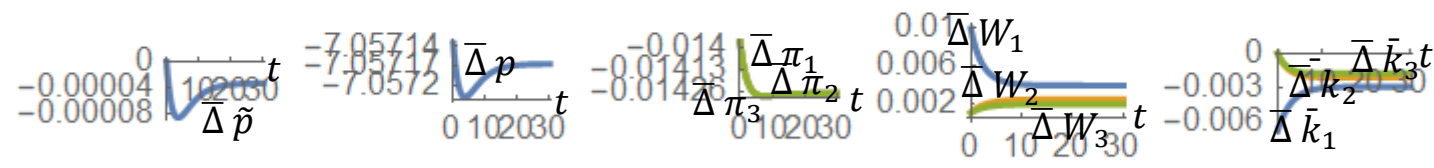

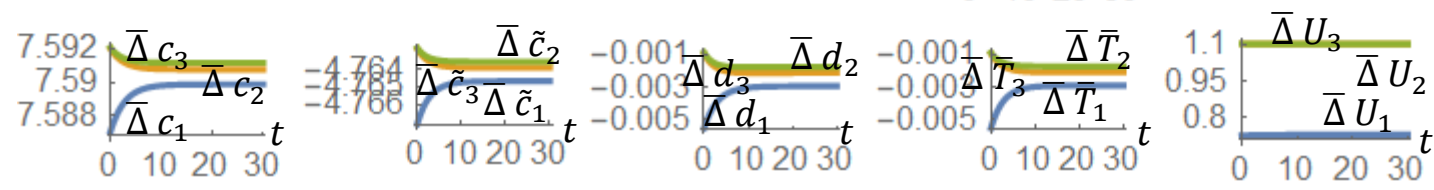

Figure 4. A Rise in Variety of Middle Goods 


\section{The total factor productivity of the final goods sector is increased}

We now study the impact that the total factor productivity of the final goods sector is increased as follows: $A: 1.4 \Rightarrow 1.5$. The simulation result is plotted in Figure 5 . The output level of the final goods sector is enhanced. The national wealth is augmented. The representative household of group 1 increases work time initially and does not change time distribution in the long term. The households of the other groups reduce work hours initially and do not change time distribution in the long term. The total labor rises initially and does not change in the long term. The labor force employed by the middle goods sector falls initially and does not change in the long term. The labor force employed by the final goods sector rises initially and does not change in the long term. Each firm produces less output and employs less labor force initially, and the variables are not changed in the long term. The profit of each firm and profit shared by each household rise. The rate of interest is augmented and is not changed in the long term. The wage rate is enhanced. The prices of middle goods and aggregate good are increased. Each household gets more wage income and own more wealth. All the households consume more final goods. Their utility levels are enhanced.
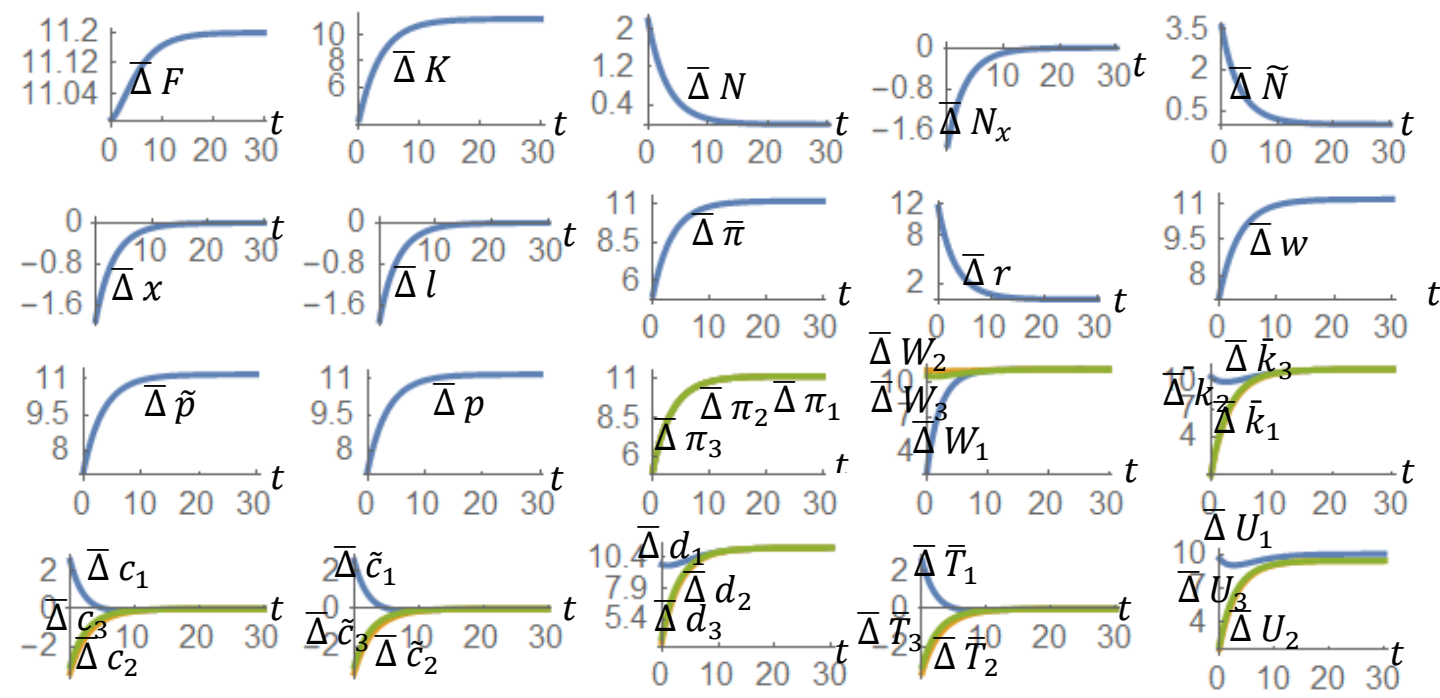

Figure 5. The Total Factor Productivity of the Final Goods Sector is Increased

\section{Group 1's propensity to consume middle goods is enhanced}

We now examine the impact that the following rise in group 1's propensity to consume middle goods: $\chi_{01}=0.1 \Rightarrow 0.12$. The simulation result is plotted in Figure 6 . The national wealth and output level of final goods sector are reduced. Group 1's work hours is increased, while the other two groups' work hours are reduced. The national labor force is increased. The middle goods sector employs more labor force, while the final goods sector employs less labor force. Each firm's profit is increased and each household gets more profit. The rate of interest rises, while the wage rate falls. Group 1 gets more wage income, while the other two groups less. The household of group 1 has less wealth, while the households in the other two groups get more. Each firm produces more and employs more labor force. The prices of middle goods fall. The household of group consumes more middle goods and less final goods, while the households in the other groups slightly change their consumption levels. 
INTERNATIONAL JOURNAL OF ACADEMIC RESEARCH IN BUSINESS AND SOCIAL SCIENCES

Vol. 9, No. 3, March, 2019, E-ISSN: 222 2-6990 @ 2019 HRMARS
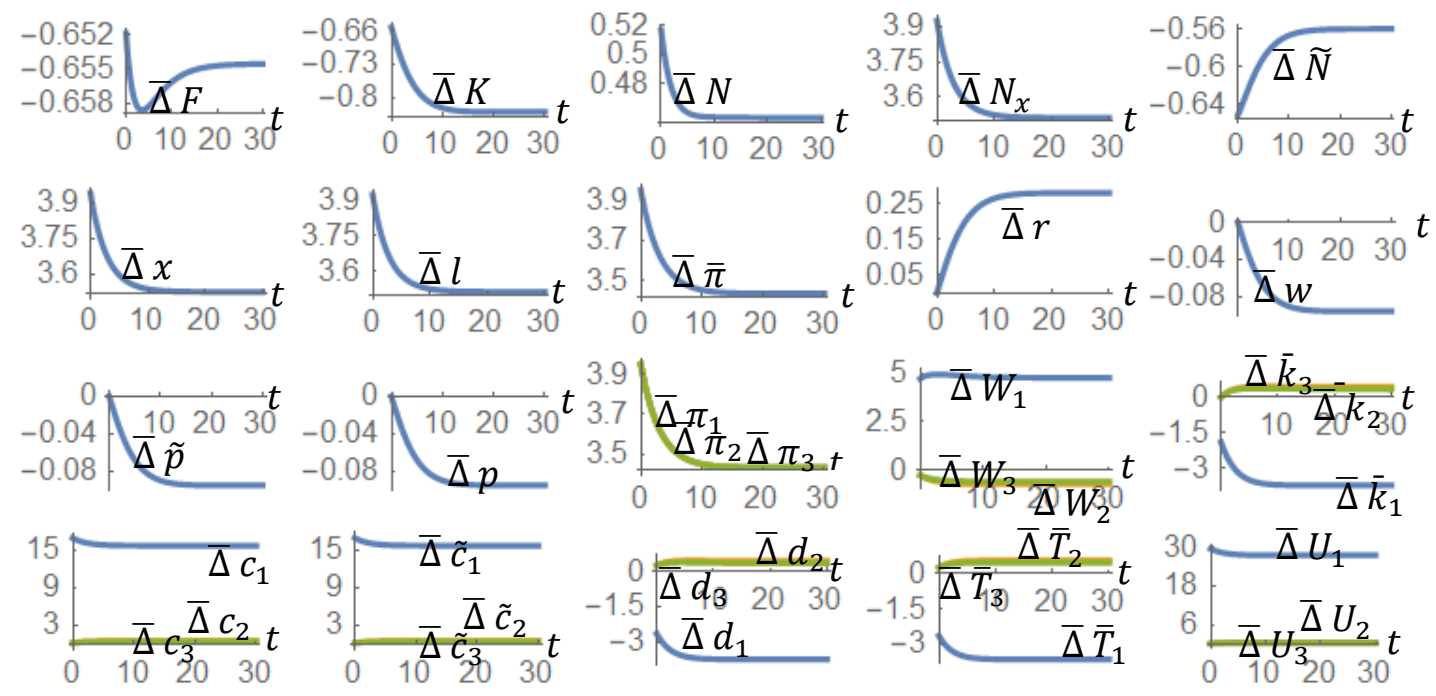

Figure 6. Group 1's Propensity to Consume Middle Goods is Enhanced

\section{Group 1's propensity to save is enhanced}

We now study what will happen to the economy if group 1's propensity to save is increased as follows: $\lambda_{01}=0.7 \Rightarrow 0.72$. The simulation result is plotted in Figure 7 . The national capital is increased and rate of interest is reduced. The wage rate is enhanced. All the households get more wage incomes. The household from group 1 works more hours initially and less hours in the long term. The households from the other two groups work more hours. The firm gets less profits initially but more in the long term. Each household shares less profits initially but more in the long term. The prices of middle goods are augmented. The household of group 1 has higher utility levels, while the households from the other groups have almost the same levels.
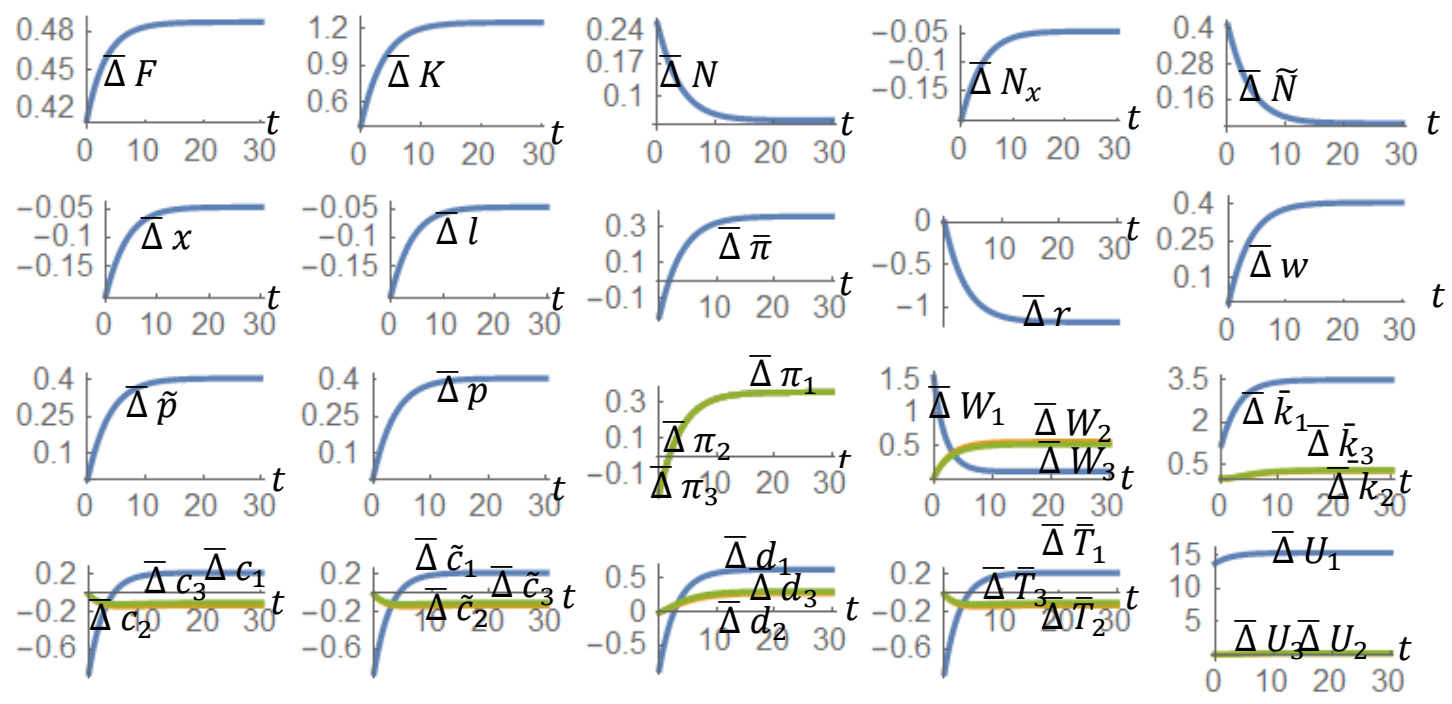

Figure 7. Group 1's Propensity to Save is Enhanced 


\section{Group 3 enhances human capital}

We now deal with the impact that the following rise in group 1's human capital on the economy: $h_{3}=$ $1 \Rightarrow 1.2$. The simulation result is plotted in Figure 8 . The national labor force is augmented. The national capital and output of the final goods sector are augmented. The final goods and middle goods sectors employ more labor force. Each firm has more profits, employs more labor force and produces more. The rate of interest falls initially and rises in the long term. The wage rate rises initially and falls in the long term. The household gets more wage income. In the long term the households of the other two groups get almost the same wage incomes. In long term the household from group 3 consumes more and has higher utility level.
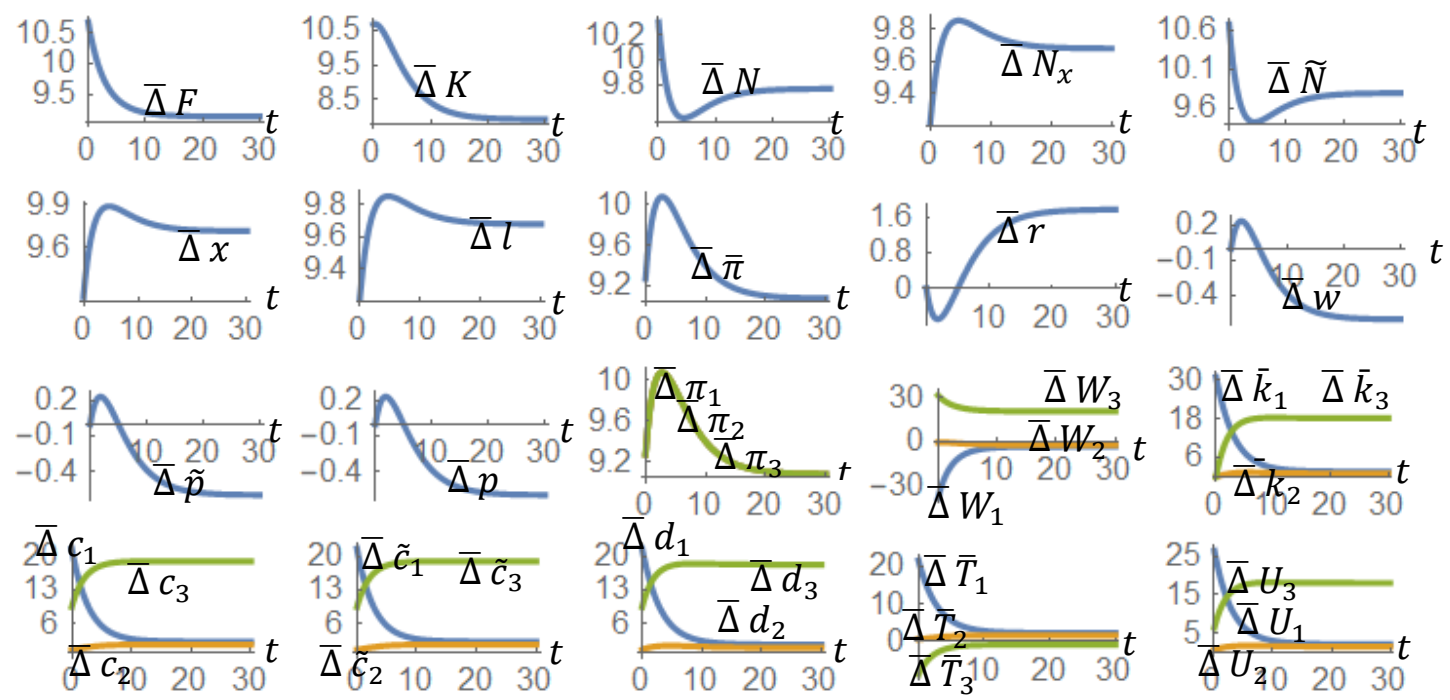

\section{Figure 8. Group 3 Enhances Human Capital}

\section{Group 3's population is increased}

We now deal with the impact that the following rise in group's population on the economy: $\bar{N}_{3}=$ $100 \Rightarrow 110$. The simulation result is plotted in Figure 9. The national capital and output of the final goods sector are increased. The rate of interest is reduced and the wage rate is enhanced. All the households get more wage incomes. The household from group 3 works more hours. The households from the other two groups work less hours. The firm gets more profits. Each household of group 2 shares less profit. Each household of the other two groups shares more profit. The prices of middle goods are reduced. The household of group 3 consumes less goods and has less wealth, while the households from the other groups consume more goods and have more wealth. The household of group 3 has lower utility level, while the households from the other groups have higher utility levels. We conclude that a population expansion of a poor group enlarges the national economy, benefits the individuals of the other groups, and deteriorates the poor household's living conditions. 
INTERNATIONAL JOURNAL OF ACADEMIC RESEARCH IN BUSINESS AND SOCIAL SCIENCES

Vol. 9, No. 3, March, 2019, E-ISSN: 222 2-6990 @ 2019 HRMARS
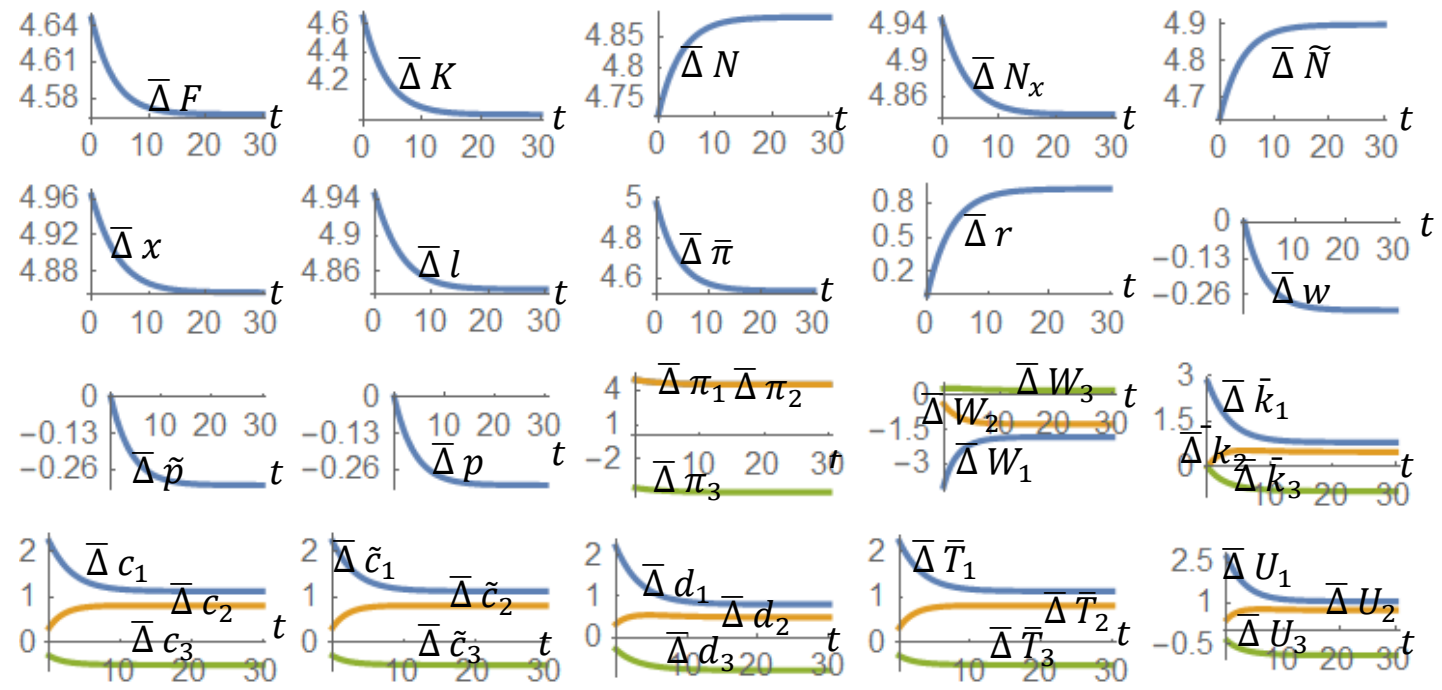

\section{Figure 9. Group 3's Population is Increased}

\section{The profit distribution is shifted}

We now deal with the impact that the following change in the profit distribution on the economy:

$\mu 1=0.3 \Rightarrow 0.32 ; \mu 2=0.3 \Rightarrow 0.29 ; \mu 3=0.4 \Rightarrow 0.39$.

We assume that the profit share of group 1 is increased, while the other two groups' are reduced. The simulation result is plotted in Figure 10. The national capital and output of the final goods sector are increased. The rate of interest is reduced and the wage rate is enhanced. The household from group 1 has more leisure time, while the households of the other groups work more hours. The household from group 1 has less wage income, while the households of the other groups receive more wage income and work more hours. The firm's profit is changed slightly. Each household of group 1 has more profit, while each household of the other two groups receives less profit. The prices of middle goods are slightly increased. Each household of group 1 enjoy more leisure time, while each household of the other two groups works more hours. The household of group 1 consumes more goods and has more wealth, while the households from the other groups consume less goods and have less wealth. The household of group 1 has higher utility level, while the households from the other groups have lower utility levels. 
INTERNATIONAL JOURNAL OF ACADEMIC RESEARCH IN BUSINESS AND SOCIAL SCIENCES

Vol. 9, No. 3, March, 2019, E-ISSN: 222 2-6990 @ 2019 HRMARS
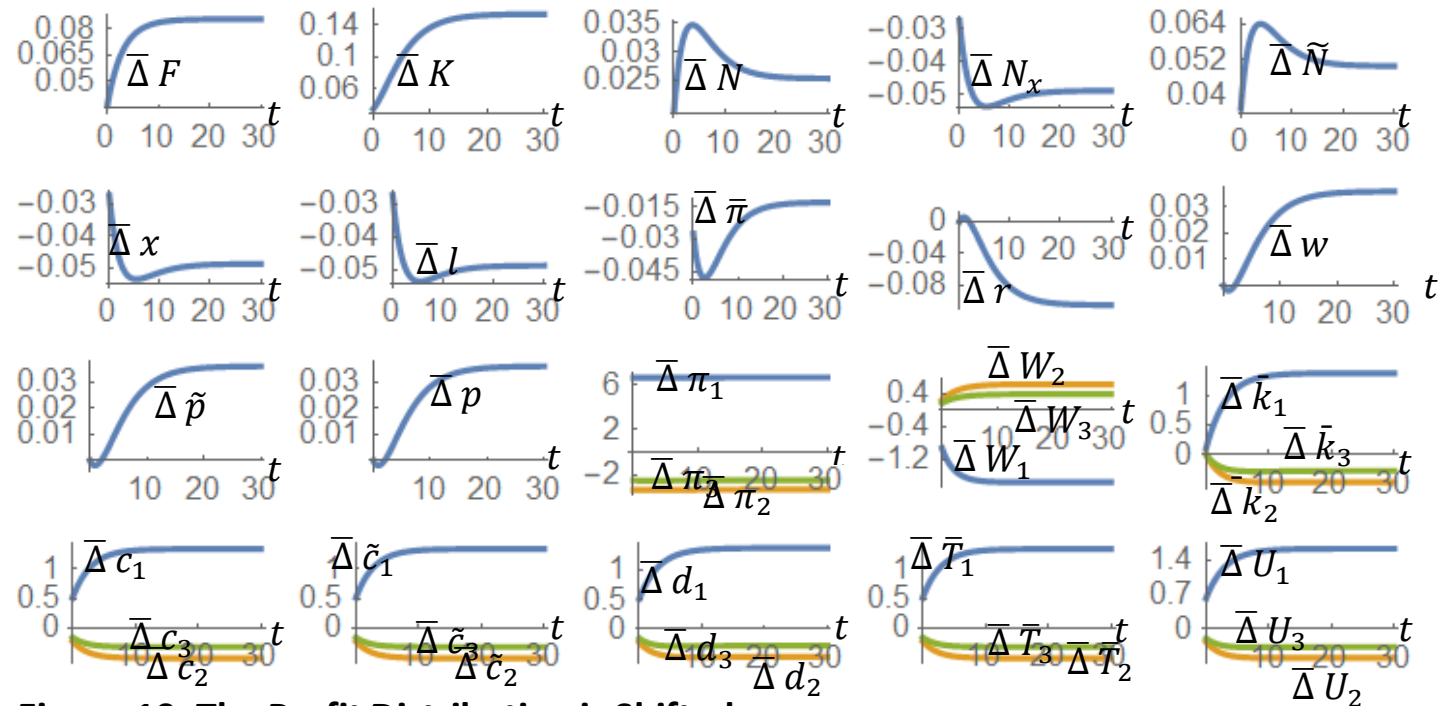

Figure 10. The Profit Distribution is Shifted

\section{Conclusion}

This study proposed an economic growth model with income and wealth distribution on the basis of Walrasian general equilibrium theory, neoclassical growth theory, and Dixit-Stiglitz monopolistic competitive theory. It made a unique contribution to the literature of economic growth with perfect competition and monopolistic competition by integrating the basic economic mechanism in the Walrasian general equilibrium model, the Solow one-sector growth model, and the Dixit-Stiglitz model. The final goods sector in our approach is based on Solow's one-sector growth model. The issues of distribution are referred to the Arrow-Debreu theory. The market mechanism of perfect competitive markets is based on traditional neoclassical growth theory. We described imperfect competition on the approach basically developed by Dixit and Stiglitz (1977). The economy in our approach is composed of two sectors. One sector is like the one-sector in the Solow model with perfect competition. The other sector is called the middle goods sector which is based on Dixit and Stiglitz's intermediates sector supplying different goods for consumption by many monopolistic competitive firms. We unified the different approaches by applying the utility function and the concept of disposable income proposed by Zhang. We also deviate from the Dixit-Stiglitz by assuming that non-zero profits are distributed to households. We built and then simulated the model for a three-group economy. We demonstrated a unique stable equilibrium point. We examined the effects of changes in the elasticity of substitution between two varieties, fixed labor cost of the middle goods firm, variety of middle goods, the total factor productivity of the final goods sector, group 1's propensity to consume middle goods, group 1's propensity to save, group 3's human capital, group 3's population, and the profit distribution. We showed how changes in these different parameters have impact on transitory processes and the long-term equilibrium structure. As there are a large amount of publications in each of the three theories and our model integrated these basic models within a comprehensive framework, we can extend and generalize the model in different ways on the basis of the literature. For instance, our distribution of profits is only a limited case of profit distribution. Profits may be shared by different agents for different uses. It can also be used for innovation. We may make human capital endogenous variables. It is important to abandon the assumption that industries of middle goods are symmetry. 


\section{Appendix: Proving the Lemma}

From (2) we get

$$
\mathrm{z} \equiv \frac{r+\delta_{k}}{w}=\frac{\bar{\beta} \widetilde{N}}{K},
$$

where $\bar{\beta} \equiv \alpha / \beta$. From (A1) and (2), we have:

$$
F=A K\left(\frac{z}{\bar{\beta}}\right)^{\beta} \text {. }
$$

From (3), we have:

$$
r=\alpha A\left(\frac{z}{\bar{\beta}}\right)^{\beta}-\delta_{k}, w=\frac{r+\delta_{k}}{z} .
$$

Insert (28) and (32) in the concept of $\hat{y}_{j}$ :

From the definition of $M$, we have

$$
\bar{y}_{j}=R \bar{k}_{j}+h_{j} T_{0} w+\pi_{j} \cdot(A 4)
$$

$$
M=\frac{1}{n \tilde{p}^{\bar{\theta} \gamma}} \sum_{j=1}^{J} \chi_{j} \bar{N}_{j} \bar{y}_{j},
$$

where we use $P_{j}=n \tilde{p}^{\bar{\theta} \gamma}$. From (A5), (31) and (32), we have

$$
\pi_{j}=\bar{\mu}_{j} \sum_{q=1}^{J} \chi_{q} \bar{N}_{q} \bar{y}_{q}-\frac{\mu_{j} \tilde{\alpha} n w}{\bar{N}_{j}},
$$

where we use (30) and

$$
\bar{\mu}_{j} \equiv \frac{\mu_{j} \vartheta}{(\tilde{\beta} / \bar{\theta})^{\bar{\theta} \gamma} \bar{N}_{j}}
$$

Insert (A6) in (A4)

$$
\bar{y}_{j}-\bar{\mu}_{j} \sum_{q=1}^{J} \chi_{q} \bar{N}_{q} \bar{y}_{q}=R \bar{k}_{j}+\tilde{\mu}_{j}
$$

where

$$
\tilde{\mu}_{j} \equiv\left(h_{j} T_{0}-\frac{\mu_{j} n \tilde{\alpha}}{\bar{N}_{j}}\right) w .
$$

Equations (A7) are linear in $\bar{y}_{j}$ and $\bar{k}_{j}$. It should be noted that $\mathrm{R}$ and $\tilde{\mu}_{j}$ are functions of $z$. It is straightforward to solve the linear equations. We express the solution in the following form:

$$
\bar{y}_{j}=\sum_{i=1}^{J} g_{i j}(z) \bar{k}_{i}+g_{0 j}(z),
$$

where $g_{i j}(z)$ and $g_{0 j}(z)$ are functions of $z$. We don't give expressions of these functions as they are too tedious. From (24), we have:

From (19) and (23), we have

$$
N_{x}=\tilde{\alpha} n+\tilde{\beta} n x .(A 9)
$$




$$
x=\sum_{j=1}^{J} \frac{\chi_{j} \bar{y}_{j} \bar{N}_{j}}{n \tilde{p}}
$$

Insert (A10) in (A9)

$$
N_{x}=\tilde{\alpha} n+\tilde{\beta} \sum_{j=1}^{J} \frac{\chi_{j} \bar{N}_{j} \bar{y}_{j}}{\tilde{p}}
$$

From (A11) and (A1), we have

$$
\frac{\mathrm{z} \mathrm{K}}{\bar{\beta}}+\tilde{\alpha} n+\tilde{\beta} \sum_{j=1}^{J} \frac{\chi_{j} \bar{N}_{j} \bar{y}_{j}}{\tilde{p}}=\mathrm{N} .
$$

Insert (34) in (A12)

$$
\frac{\mathrm{z}}{\bar{\beta}} \sum_{j=1}^{J} \bar{k}_{j} \bar{N}_{j}+\tilde{\alpha} n+\tilde{\beta} \sum_{j=1}^{J} \frac{\chi_{j} \bar{N}_{j} \bar{y}_{j}}{\tilde{p}}=\mathrm{N} .
$$

By (1) and $T_{j}+\bar{T}_{j}=T_{0}$, we get

$$
N=\tilde{T}_{0}-\sum_{j=1}^{J} h_{j} \bar{N}_{j} \bar{T}_{j}
$$

where

$$
\tilde{T}_{0} \equiv \sum_{j=1}^{J} h_{j} T_{0} \bar{N}_{j}
$$

Insert (12) in (A14)

$$
N=\tilde{T}_{0}-\frac{1}{w} \sum_{j=1}^{J} \bar{N}_{j} \sigma_{j} \bar{y}_{j}
$$

Insert (A15) in (A13)

where

$$
\frac{\mathrm{z}}{\bar{\beta}} \sum_{j=1}^{J} \bar{k}_{j} \bar{N}_{j}+\sum_{j=1}^{J} \bar{N}_{0 j} \bar{y}_{j}=\tilde{T}_{0}-\tilde{\alpha} n,
$$

Insert (A8) in (A16)

$$
\bar{N}_{0 j} \equiv\left(\frac{\chi_{j} \tilde{\beta}}{\tilde{p}}+\frac{\sigma_{j}}{w}\right) \bar{N}_{j}
$$

where

$$
\sum_{j=1}^{J} \tilde{g}_{j} \bar{k}_{j}=\tilde{T}_{0}-\tilde{\alpha} n-g_{0},(A 17)
$$

$$
\tilde{g}_{j} \equiv \frac{z \bar{N}_{j}}{\bar{\beta}}+g_{j}, \quad g_{j} \equiv \sum_{m=1}^{J} \bar{N}_{0 m} g_{j m}, g_{0} \equiv \sum_{m=1}^{J} \bar{N}_{0 m} g_{0 m} .
$$


Solve (A17) in $\bar{k}_{1}$

$$
\bar{k}_{1}\left(z,\left\{\bar{k}_{j}\right\}\right)=\left(\tilde{T}_{0}-\tilde{\alpha} n-g_{0}-\sum_{j=2}^{J} \tilde{g}_{j} \bar{k}_{j}\right) \frac{1}{\tilde{g}_{1}} .
$$

In summary, we showed that all the variables can be expressed as functions of $z$ and $\left\{\bar{k}_{j}\right\}$ by the following procedure: $r$ and $w$ by (A3) $\rightarrow \bar{k}_{1}$ by (A18) $\rightarrow \tilde{p}$ by (30) $\rightarrow \bar{y}_{j}$ by (A8) $\rightarrow \bar{T}_{j}, d_{j}$, $s_{j}$ by (12) $\rightarrow K$ by (32) $\rightarrow \widetilde{N}$ by (A1) $\rightarrow \pi_{j}$ by (A6) $\rightarrow x$ by (A9) $\rightarrow N_{x}$ by (A9) $\rightarrow N$ by (35) $\rightarrow F$ by (A2) $\rightarrow \tilde{c}_{j}$ by (19) $\rightarrow$ $p$ by $(20) \rightarrow l$ by $(24) \rightarrow \varphi$ by $(21) \rightarrow \bar{\pi}$ by $(26) \rightarrow U_{j}$ by (10).

From the procedure and (22), we have

$$
\begin{aligned}
& \dot{\bar{k}}_{1}(t)=\Phi_{0}\left(z(t),\left\{\bar{k}_{j}(t)\right\}\right) \equiv s_{1}(t)-\bar{k}_{1}(t), \\
& \dot{\bar{k}}_{j}(t)=\Phi_{j}\left(z(t),\left\{\bar{k}_{j}(t)\right\}\right) \equiv s_{j}(t)-\bar{k}_{j}(t) .
\end{aligned}
$$

Take derivatives of (A18) with respect to time

$$
\dot{\bar{k}}_{1}=\frac{\partial \bar{k}_{1}}{\partial z} \dot{z}+\sum_{j=2}^{J} \frac{\partial \bar{k}_{1}}{\partial \bar{k}_{j}} \dot{\bar{k}}_{j}
$$

From (A18)-(A21), we have:

$$
\dot{z}=\Phi_{1}\left(z(t),\left\{\bar{k}_{j}(t)\right\}\right) \equiv\left(\Phi_{0}-\sum_{j=2}^{J} \frac{\partial \bar{k}_{1}}{\partial \bar{k}_{j}} \dot{\bar{k}}_{j}\right)\left(\frac{\partial \bar{k}_{1}}{\partial z}\right)^{-1}
$$

Equations (A22) and (A20) determine the motion of $z(t)$ and $\left\{\bar{k}_{j}(t)\right\}$. We thus confirmed the Lemma.

\section{References}

Arrow K.J. and Debreu, G. (1954) Existence of an equilibrium for a competitive economy. Econometrica, 22(3), 265-90.

Arrow, K.J. and Hahn, F.H. (1971) General Competitive Analysis. San Francisco: Holden-Day, Inc.

Azariadis, C. (1993) Intertemporal Macroeconomics. Oxford: Blackwell.

Barro, R.J. and X. Sala-i-Martin (1995) Economic Growth. New York: McGraw-Hill, Inc.

Becker, G.S. (1965) A theory of the allocation of time. Economic Journal, 75(29), 493-517.

Becker, G. S. (1976) The Economic Approach to Human Behavior. Chicago: The University of Chicago Press.

Ben-David, D. and Loewy, M.B. (2003) Trade and neoclassical growth model. Journal of Economic Integration, 18(1), 1-16.

Benassy, J.P. (1996) Taste for variety and optimum production patterns in monopolistic competition. Economics Letters, 52(1), 41-7.

Bertoletti, P. and Etro, F. (2015) Monopolistic competition when income matters. The Economic Journal, 127(603), 1217-43.

Burmeister, E. and Dobell, A.R. (1970) Mathematical Theories of Economic Growth. London: Collier Macmillan Publishers. 
INTERNATIONAL JOURNAL OF ACADEMIC RESEARCH IN BUSINESS AND SOCIAL SCIENCES

Vol. 9, No. 3, March, 2019, E-ISSN: 222 2-6990 @ 2019 HRMARS

Campbell, J.Y. and Ludvigson, S. (2001) Elasticities of substitution in real business cycle models with home production. Journal of Money, Credit and Bankings, 33(4), 847-875.

Chang, W.W. (2012) Monopolistic competition and product diversity: Review and extension. Journal of Economic Surveys, 26(5), 879-910.

Dana, R.A, Florenzano, M., and Levy, D. (1989) Production prices and general equilibrium prices: A long-run property of a Leontief economy. Journal of Mathematical Economics, 18(3), 263-80.

Debreu, G. (1959) Theory of Value: An Axiomatic Analysis of Equilibrium. Yale University Press, London.

Diewert, W. (1977) Walras' theory of capital formation and the existence of a temporary equilibrium. In: Schwödiauer, G. (Ed.) Equilibrium and Disequilibrium in Economic Theory. Dordrecht: Reidel.

Dixit, A. and Stiglitz, J.E. (1977) Monopolistic competition and optimum product diversity. American Economic Review, 67(3), 297-308.

Edmonds, E.V. and Pavcnik, N. (2006) Trade liberalization and the allocation of labor between households and markets in a poor country. Journal of International Economics, 69(2), 272-95.

Eatwell, J. (1987) Walras' theory of capital, In: Eatwell, J., Milgate, M., and Newmann, P. (Eds.) The New Palgrave Dictionary of Political Economy. London: MacMillan.

Ferber, M.A. and Green, C.A. (2007) Career of family: What choices do college women have? Journal of Labor Research, 24(1), 143-51.

Gomme, P., Kydland, F.E., and Rupert, P. (2001) Home production meets time to build. The Journal of Political Economy, 109(5), 1115-31.

Goodfriend, M. and McDermott, J. (1995) Early development. American Economic Review, 85(2), 116-33.

Grossman, G.M. and Helpman, E. (1990) Comparative advantage and long-run growth. The American Economic Review, 80(4), 796-815.

Gutierrez, M. (2003, eds.) Macro-Economics: Making Gender Matter. London: Zed Books.

Impicciatore, G., Panaccione, L., and Ruscitti, F. (2012) Walras's theory of capital formation: An intertemporal equilibrium reformation. Journal of Economic Theory, 106(2), 99-118.

Jones, L. and Manuelli, R.E. (1997) The sources of growth. Journal of Economic Dynamics and Control, 21(1), 75-114.

Kelly, M. (1997) The dynamics of Smithian growth. Quarterly Journal of Economics, 112(3), 939-64.

Krugman, P.R. (1979) A model of innovation, technology transfer, and the world distribution of income. Journal of Political Economy, 87(2), 253-66.

Krugman, P.R. (1980) Scale economies, product differentiation, and the pattern of trade. The American Economic Review, 70(5), 950-59.

Lancaster, K. (1980) Intra-industry trade under perfect monopolistic competition. Journal of International Economics, 10(2), 151-75.

Mas-Colell, A., Whinston, M.D. and Green, J.R. (1995) Microeconomic Theory. New York: Oxford University Press.

Montesano, A. (2008) A restatement of Walras' theory of capitalization and money. History of Economics Review, 47(Winter), 86-109.

Morishima, M. (1964) Equilibrium, Stability and Growth. Oxford: Oxford University Press.

Morishima, M. (1977) Walras' Economics. Cambridge: Cambridge University Press. 
Nocco, A., Ottaviano, G.L.P., and Salto, M. (2017) Monopolistic competition and optimum product selection: Why and how heterogeneity matters. Research in Economics, 71(4), 704-17.

Parenti, M., Ushchev, P., and Thisse, J.F. (2017) Toward a theory of monopolistic competition. Journal of Economic Theory, 167(January), 86-115.

Romer, P.M. (1990) Endogenous technological change. Journal of Political Economy, 98(2), S71-S102.

Solow, R. (1956) A contribution to the theory of economic growth. Quarterly Journal of Economics, 70(1), 65-94.

Spence, M. (1976) Product selection, fixed costs and monopolistic competition. Review of Economic Studies, 43(2), 217-35.

Stotsky, J.G. (2006) Gender and Its Relevance to Macroeconomic Policy: A Survey. IMF Working Paper, WP/06/233.

Tassel, E.V. (2004) Household bargaining and microfinance. Journal of Development Economics, 74(2), 449-68.

Tirole, J. (1988) The Theory of Industrial Organization. Cambridge: MIT Press.

Walras, L. (1874) Elements of Pure Economics, translated from the French by W. Jaffé, 1954. London: Allen and Unwin.

Waterson, M. (1984) Economic Theory of the Industry. Cambridge: Cambridge University Press.

Zhang, W.B. (1993) Woman's labor participation and economic growth - creativity, knowledge utilization and family preference. Economics Letters, 42(1), 105-10.

Zhang, W.B. (2005) Economic Growth Theory. Ashgate, London.

Zhang, W.B. (2008) International Trade Theory: Capital, Knowledge, Economic Structure, Money and Prices over Time and Space. Berlin: Springer.

Zhang, W.B. (2018) An integration of Solow's growth and Dixit-Stiglitz's monopolistic competition models. SPOUDAI Journal of Economics and Business, 64(4), 3-19. 